\title{
Treatment seeking behavior for sexually transmitted infections/reproductive tract infections among married women in urban slums of Mumbai, India
}

\author{
Poonam P. Shingade ${ }^{l}$, Yasmeen Kazi ${ }^{2}$, Madhavi $L H^{3}$ \\ ${ }^{1}$ Assistant Professor; ${ }^{3}$ Professor and Head of the Department; Department of Community Medicine, ESIC Medical \\ College, Gulbarga, India. ${ }^{2}$ Assistant Professor, Department of Community Medicine, Topiwala National Medical College, \\ Mumbai, India.
}

\begin{abstract}
Sexually Transmitted Infections/Reproductive Tract Infections (STIs/RTIs) are a major public health problem and a leading cause of morbidity among men and women in developing countries. The aim of the study is to explore treatment seeking behavior among the married women of reproductive age presented with symptoms of STI/RTI. A hospital-based observational study was carried out at the STI/RTI Clinic of Urban Health Centre, Shivaji Nagar, Govandi, Mumbai, India. The study involved a total of 273 married females who attended clinic for their symptoms during January to March 2012. Patients were interviewed using a pretested questionnaire to explore the detail of the treatment seeking behavior regarding STIs/RTIs. Out of total women who participated in the study, only $47.6 \%$ of the women with STIs/RTIs symptoms sought health care. Among those who did not seek treatment, 58.65\% females were belonging to 21-25 years of age group. Maximum 65.6\% females who were illiterate had not sought any treatment for symptoms of these diseases as compared to $65 \%$ who had taken treatment for the presented symptoms who were educated up to higher secondary and above level. $62.5 \%$ females belonging to class $\mathrm{V}$ had never sought treatment as compared to $100 \%$ women who were classified to class I. The poor health seeking behavior was associated with literacy and socioeconomic class of the participants. Private sector was the most favored place for taking treatment by them. Commonest reason for not seeking treatment was no female doctor at clinic. Information, Education and Communication (IEC) sessions, about STI symptoms and the benefits of treatment, especially targeted at women and low socioeconomic groups might be an immediately feasible measure that will help to reduce the burden of the disease.
\end{abstract}

Keywords: STIs/RTIs, Treatment seeking behavior, Married women, Urban slums, India.

\section{Introduction}

Sexually Transmitted Infections/Reproductive Tract Infections (STIs/RTIs) are a major public health problem and a leading cause of morbidity among men and women in developing countries. ${ }^{1,2}$ STIs/RTIs rank second as a cause of healthy life lost among women in the reproductive age group. WHO estimates show that in 1995,150 million new cases of RTI/STIs occurred in South East Asia alone. ${ }^{3}$

STIs/RTIs may be either asymptomatic or symptomatic. ${ }^{4}$ Regardless of the presence or absence of symptoms all of them can lead to major complications if left untreated. ${ }^{5}$ Most STIs are, however symptomatic ${ }^{4}$ and so a simple symptom survey could be used to screen for the presence of such infections. WHO had adopted syndromic case management which is based on symptoms of the patients, offers many benefits in this effort. ${ }^{6}$

However in spite of the availability of low cost and appropriate technologies to manage STIs/RTIs in the primary health care setting, most of the STIs remain hidden and unrecorded and a very small proportion of people (5-10\%) suffering from the disease attend government health facilities due to existing taboos and inhibitions regarding sexual and reproductive health. ${ }^{4}$

\section{Practice Points}

- STIs/RTIS are a major public health problem and a leading cause of morbidity among men and women in developing countries like India.

- In spite of the availability of low-cost and appropriate technologies to manage STI/sRTIs in the PHC setting, most of the infections remain hidden and unrecorded.

- The study recorded that only $47.6 \%$ of the participants who had the symptom of STIs/RTIs had sought treatment preferably in private hospitals.

- The poor health seeking behavior among the married women was associated with literacy and their socioeconomic condition and mostly noted in younger age groups.

- Awareness about the modes of transmission, methods of prevention and consequences of untreated or partially treated diseases does modify treatment seeking behavior.

They hesitate to discuss their reproductive health problems especially, due to shame and

Correspondence: Dr. Poonam P. Shingade, Assistant Professor, Department of Community Medicine, ESIC Medical College, Gulbarga India. Email: dr.poonam.ps@gmail.com. 
embarrassment. ${ }^{7,8}$ Symptoms of RTI/sSTIs are often considered to be not serious, or self-limiting or simply a normal consequence of marriage and child bearing, and therefore not severe enough to warrant attention. ${ }^{9}$ Lack of economic independence, restriction to physical mobility of women in most communities, poor quality of care, inaccessibility of services, non-availability of female physicians at health care facility and high costs are other obstacles to health care seeking for RTIs/ STIs. ${ }^{10,11}$

According to a study done in China by Choi et al., ${ }^{12}$ the main sources of STD treatments among their study participants were private physicians followed by public clinics and drugstores and factors associated with treatment-seeking behaviors differed by gender. Another study carried out among women of the reproductive age attending the gynecology and family planning outpatient clinics of the Lagos State University Teaching Hospital explored that there is a reluctance to seek health care, which could cause delay in appropriate diagnosis and treatment. The most common treatment - seeking behavior was self - medication through private pharmacies. $^{13}$

A study conducted by Bhanderi \& Kannan ${ }^{11}$ in Gujrat, India found that a lower sense of need, the cost of care and societal barriers were the reasons for not seeking care. A study done by Hegde et al., ${ }^{14}$ in Karnataka, India showed that only $60 \%$ sought some form of treatment for the symptoms of STI/RTI and out of those who sought treatment and out of the total $69 \%$ approached a private healthcare facility. A study conducted in urban slums of Mumbai, India revealed that major predictors of both symptoms of reproductive infections and treatment seeking behavior from multivariate analysis are age, education, wealth, region and awareness about RTIs/STIs. ${ }^{15}$

It is a common problem in India for women in the reproductive age group to suffer from reproductive illnesses and not to seek care. This paper is an attempt to assess treatment seeking behavior among ever married women of the reproductive age group who had reported STIs/RTIs symptoms at the STI/RTI Clinic of Urban Health Centre, Shivaji Nagar, Govandi, Mumbai, India. The aims of the study were to examine the association between the socio-demographic profile and treatment seeking behavior of the respondents and to assess the reasons for not seeking treatment for the symptoms of STIs/RTIs.

\section{Materials and methods}

This hospital based descriptive, cross-sectional study was carried out in urban slums of Mumbai at STI/RTI clinic of Urban Health Centre (UHC) Shivaji Nagar, Govandi, which is affiliated to Department of Community Medicine, Topiwala National Medical College and B.Y.L. Nair Hospital, during January 2012 to March 2012. Approval of the Institutional Ethics Committee was sought and granted before the start of study. Total number of 273 females attended STI/RTI Clinic during this duration. All married and willing women in the age group 15 to 45 years constituted the sampling frame. The nature and purpose of the study was explained to the participant maintaining the utmost confidentiality. Informed and written consent of study population was obtained.

The data was collected by interview methods using a predesigned, pretested, semi-structured questionnaire to collect demographic characteristics of the respondents (i.e. name, age, occupation, religion) and socioeconomic class of participants was decided by using modified kuppuswamy classification. ${ }^{16}$ Data collection tool also includes questions regarding symptoms of patients and duration of the illness. A participant was said to have RTIs/STIs symptoms if she had experienced one of the following symptoms in the past 12 months: Abnormal vaginal discharge, ulcers or boils in and around the genital region, pain in lower abdomen which was not related to menses, itching over genitals, pain or burning sensation during urination, swelling in the groin and painful blister like lesions in and around vagina, pain during sexual intercourse and spotting after sexual intercourse. ${ }^{17}$ The participant was defined to have sought health care, if she has approached any of the health care system on experiencing RTIs/STIs related symptoms with the purpose of finding a cure. ${ }^{18}$ Information regarding the treatment seeking behavior includes places where treatment had taken. Reasons for not seeking the treatment were also noted.

The data was analyzed using SPSS 15. Results are obtained in terms of proportions. Chi square test was used to prove the associations between sociodemographic characteristics and treatment seeking behavior.

\section{Results}

A total 273 married women were included in the study. According to Table 1, most of the participants were Muslim (86.8\%), unemployed (91.57\%) and living in nuclear type of family $(60.4 \%)$. Highest number of women ( $34.4 \%$ ) were in the age group of 26-30 years followed by $87(31.9 \%)$ in the age group of $21-25$ years.

More than half $(52.4 \%)$ of the females have not taken any kind of treatment. Approximately (48\%) of females had received treatment for current or past illness of STIs/RTIs from either government and private hospitals, or local doctors for their symptoms related to STIs/RTIs.

Among the females who had not sought any treatment for STIs/RTIs, most of them were in age group of 2125 years, $(88.1 \%)$ were Muslim by religion, (39.9\%) were educated up to primary level, $(89.5 \%)$ were unemployed, and (39.2\%) were belonging to class III of socioeconomic status. Most of the females (65.6\%), who did not sought any treatment, were illiterate as compared to the most of the females $(65.0 \%)$, who had taken treatment, were educated up to higher secondary and above level. 
Table 1: Association between the socio-demographic profile and treatment seeking behavior

\begin{tabular}{|c|c|c|c|c|c|}
\hline \multirow{2}{*}{$\begin{array}{l}\text { Socio-demographic } \\
\text { profile }\end{array}$} & \multirow{2}{*}{$\begin{array}{l}\text { Participants } \\
(\mathrm{n}-273)\end{array}$} & \multicolumn{2}{|c|}{ Treatment taken } & \multirow[t]{2}{*}{$\mathbf{X}^{2}$} & \multirow[t]{2}{*}{$p$-value } \\
\hline & & No & Yes & & \\
\hline \multicolumn{4}{|l|}{ Age (in year) } & \multirow{7}{*}{5.017} & \multirow{7}{*}{0.414} \\
\hline $16-20$ & $11(4 \%)$ & $6(54.5 \%)$ & $5(45.5 \%)$ & & \\
\hline $21-25$ & $87(31.9 \%)$ & $51(58.6 \%)$ & $36(41.4 \%)$ & & \\
\hline $26-30$ & $94(34.4 \%)$ & $47(50.0 \%)$ & $47(50.0 \%)$ & & \\
\hline $31-35$ & $53(19.4 \%)$ & $29(54.7 \%)$ & $24(45.3 \%)$ & & \\
\hline $36-40$ & $21(7.7 \%)$ & $7(33.3 \%)$ & $14(66.7 \%)$ & & \\
\hline $41-45$ & $7(2.6 \%)$ & $3(42.9 \%)$ & $4(57.1 \%)$ & & \\
\hline \multicolumn{4}{|l|}{ Religion } & \multirow{3}{*}{0.442} & \multirow{3}{*}{0.506} \\
\hline Hindu & $36(13.2 \%)$ & $17(47.2 \%)$ & $19(52.8 \%)$ & & \\
\hline Muslim & $237(86.8 \%)$ & $126(53.2 \%)$ & $111(46.8 \%)$ & & \\
\hline \multicolumn{4}{|l|}{ Type of family } & \multirow{4}{*}{0.078} & \multirow{4}{*}{0.962} \\
\hline Joint & $90(33 \%)$ & $47(52.2 \% 0$ & $43(47.8 \%)$ & & \\
\hline Nuclear & $165(60.4 \%)$ & $86(52.1 \%)$ & $79(47.9 \%)$ & & \\
\hline Three Generation & $18(6.6 \%)$ & $10(55.6 \%)$ & $8(44.4 \%)$ & & \\
\hline \multicolumn{4}{|l|}{ Education } & \multirow{5}{*}{24.77} & \multirow{5}{*}{$<0.001$} \\
\hline Illiterate & $64(23.4 \%)$ & $42(65.6 \%)$ & $22(34.4 \%)$ & & \\
\hline Primary & $86(31.5 \%)$ & $57(66.3 \%)$ & $29(33.7 \%)$ & & \\
\hline Secondary & $83(30.4 \%)$ & $30(36.1 \%)$ & $53(63.9 \%)$ & & \\
\hline HSC and above & $40(14.7 \%)$ & $14(35.0 \%)$ & $26(65.0 \%)$ & & \\
\hline \multicolumn{4}{|l|}{ Occupation } & \multirow{5}{*}{2.674} & \multirow{5}{*}{0.445} \\
\hline Skilled & $7(2.6 \%)$ & $4(57.1 \%)$ & $3(42.9 \%)$ & & \\
\hline Semiskilled & $12(4.4 \%)$ & $9(75 \%)$ & $3(25.0 \%)$ & & \\
\hline Unskilled & $4(1.5 \%)$ & $2(50.0 \%)$ & $2(50.0 \%)$ & & \\
\hline Unemployed & $250(91.6 \%)$ & $128(51.2 \%)$ & $122(48.8 \%)$ & & \\
\hline \multicolumn{4}{|l|}{ Socio-economic status } & \multirow{6}{*}{12.77} & \multirow{6}{*}{0.012} \\
\hline Class I & $5(1.5 \%)$ & 0 & $5(100 \%)$ & & \\
\hline Class II & $28(10.3 \%)$ & $9(32.1 \%)$ & $19(67.9 \%)$ & & \\
\hline Class III & $51(18.7 \%)$ & $26(51 \%)$ & $25(49 \%)$ & & \\
\hline Class IV & $133(48.7 \%)$ & $73(54.9 \%)$ & $60(45.10 \%)$ & & \\
\hline Class V & $56(20.5 \%)$ & $35(62.5 \%)$ & $21(37.5 \%)$ & & \\
\hline
\end{tabular}

There is no statistically significant association between the age, religion, type of family and treatment seeking behavior. But the education and socioeconomic class had showed a significant association with treatment seeking behavior. More than $(62 \%)$ of females belonging to class $\mathrm{V}$ of socioeconomic class had never sought treatment as compared to $5(100 \%)$ women who had taken treatment.
Fig. 1 shows that maximum participants had taken treatment from private sector $(64.62 \%)$ followed by government sector $(28.46 \%)$. Fig. 2 shows the reasons for not seeking treatment. The main reasons include: absence of female doctor at the clinic $(23.8 \%)$, perceived symptoms as normal and thought that there was no need for treatment (12.6\%), felt the symptoms would disappear after some days (18.9\%),

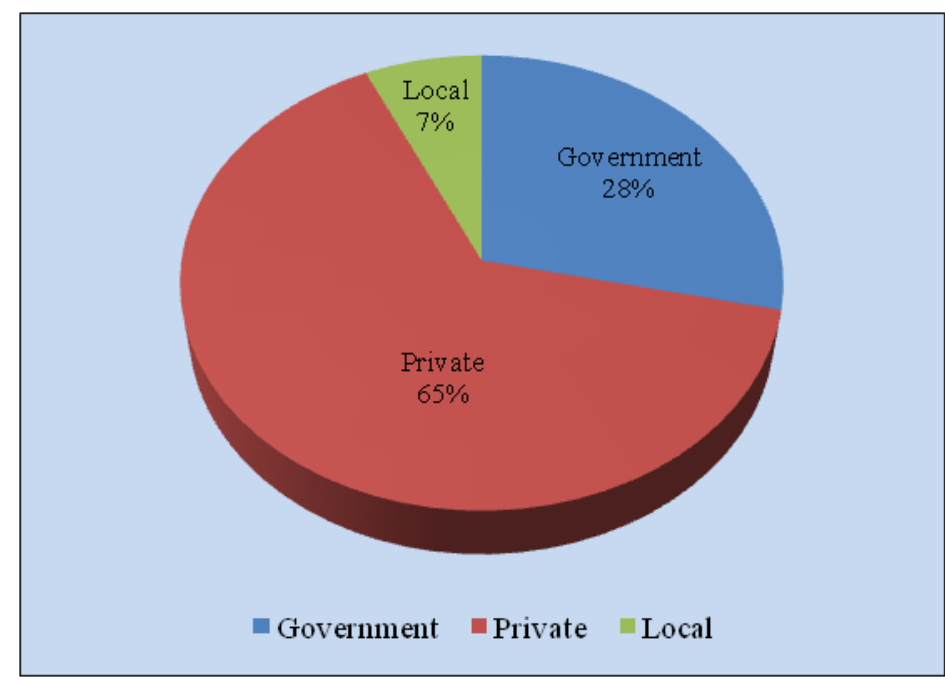

Fig 1: Sources from where study participants seek treatment 


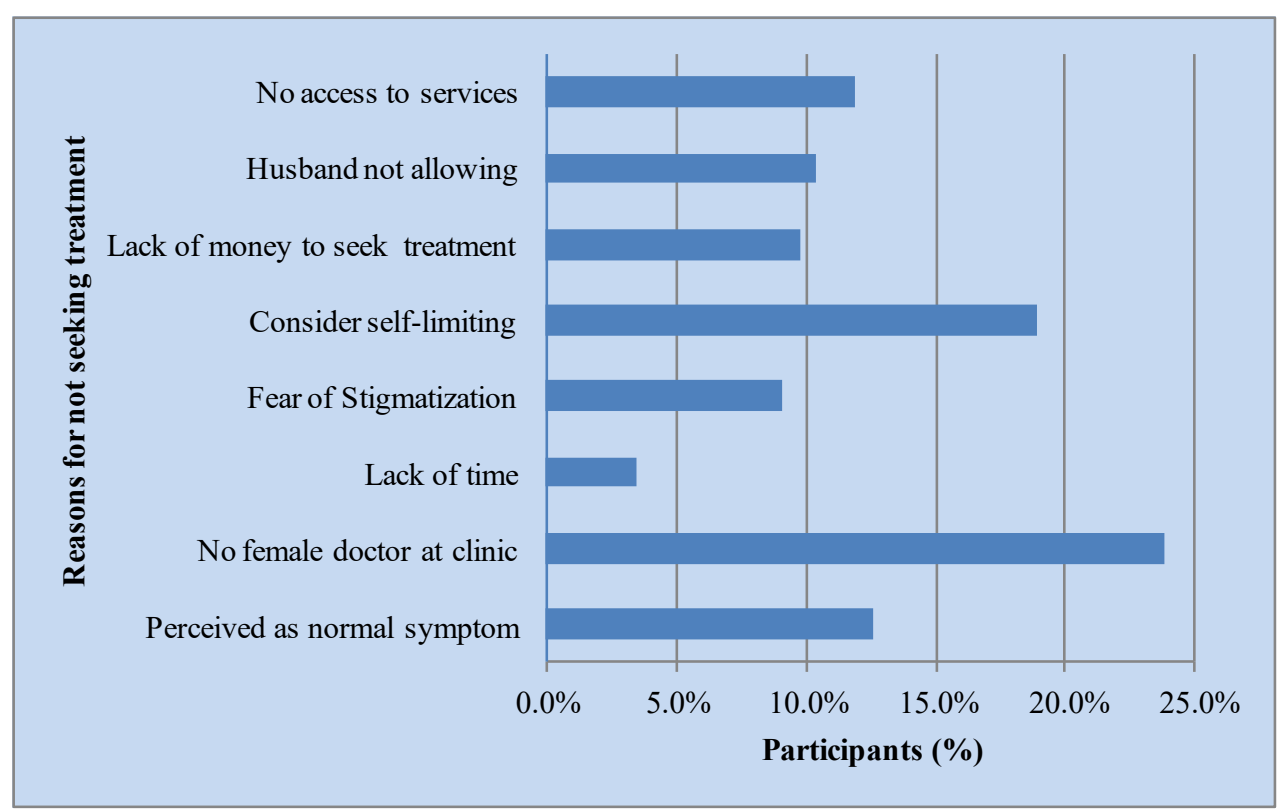

Fig 2: Reasons for not seeking treatment among the study participants

no easy access to healthcare services (11.9\%) females and husband (10.4\%) didn't not allow their wives to seek treatment.

\section{Discussion}

The observation from our study is that a significant proportion of symptomatic women do not seek care. Out of total, only $(47.6 \%)$ of the women with STIs/RTIs symptoms sought treatment. This proportion is higher than that reported in a study done by Kumar et al. ${ }^{19}$ $(30.6 \%)$, Prasad et al. ${ }^{20}$ (35\%) in Rajasthan and Tamil Nadu respectively. Among the females who have sought treatment, private hospitals were preferred than the government hospitals.

Another study carried out among the married women in Tamil Nadu demonstrated that more than half of the respondents $(51.45 \%)$ sought treatment for RTIs/STIs symptoms and among them $(62.9 \%)$ visited private health care facility and $32.6 \%$ utilized government health care facility. ${ }^{21}$ In Indian scenario the reasons may be lack of privacy, lack of a female doctor at the health facility at the government health facilities. Among those who did not seek treatment, maximum were in 21-25 years of age group, indicating tendency of not seeking treatment in younger females who are at maximum risk. However, the association was not statistically significant.

Religion and type of family had not shown association may be due to uneven distribution among them. In contrast, the study conducted by Mani et al..$^{21}$ found that health care seeking behavior was significantly associated with age group, religion, occupational status, and type of family. Present study highlighted that higher the education of the women, greater tendency to seek the treatment for their symptoms may be due to awareness about the diseases and complications if they are left untreated and there is a statistically significant association between the two.
Improved socioeconomic status seemed to have positive impact on treatment seeking behavior. The role of socioeconomic status in the development of STIs has been highlighted in a number of studies. ${ }^{22}$ A study from Accra among women with incomplete abortions also showed higher rates of bacterial colonization of the genital tract in women of lower socioeconomic status. ${ }^{13}$ Low socioeconomic status is associated with greater risk of sexual behaviour ${ }^{24}$ and this would lead to a higher incidence of STIs. In a study by Adanu et al. ${ }^{25}$ showed that respondents who sought treatment or advice were of higher educational level than those who were illiterate. Our study reported the key reasons for not seeking treatment as non availability of female doctors at clinic and respondents perceived morbidity as normal. The two main reasons for not seeking care reported in a study conducted by Adanu et al. ${ }^{25}$ were symptoms were not considered to be serious (40.2\%) and higher cost of care which was was considered unaffordable $(23.3 \%)$. The majority of women in a study done by Bhanderi \& Kannan ${ }^{11}$ among ever married women of slums of Rajkot city, Gujarat mentioned the reason for not seeking care as treatment was unnecessary.

There are limitations regarding the applicability of the study results to general population as study was conducted in urban slums based in hospital. Moreover, small sample size is another limitation of the study.

\section{Conclusion}

Despite a higher proportion of women presenting with RTI/STI symptoms, nearly half of the study participants sought treatment for their symptoms. The poor health seeking behavior was associated with literacy and socioeconomic class of the participants. Private sector was the most favored place for taking treatment by participants followed by the government one. Commonest reason for not seeking treatment was absence of female doctor at clinic. Our study suggest 
that designing health education messages through various Information, Education and Communication (IEC) sessions, about STI symptoms and the benefits of treatment, especially targeted at women and low socioeconomic groups might be an immediately feasible measure that can be implemented to reduce the burden of the disease.

\section{Acknowledgement}

The authors deeply acknowledges the support rendered by the staff of UHC, Govandi, Mumbai. They wish to convey their full appreciation to Dr. Anil Reddy, Assistant Professor, Department of Surgery, GIMS, Gulbarga, Karnataka, India for his critical review and sophisticated editing of this paper.

\section{Conflict of interest}

The authors declare no conflict of interest.

\section{References}

1. De Schryver A, Meheus A. Epidemiology of sexually transmitted diseases: the global picture. Bull World Health Organ. 1990;68(5):639-54.

2. Vishwanath S, Talwar V, Prasad R, Coyaji K, Elias CJ. Syndromic management of vaginal discharge among women in a Reproductive Health Clinic in India. Sex Transm Infect 2000;76(4):303-6.

3. Issac RC. An Intervention Programme for RTIs among women in a selected area in Rural Tamil Nadu, India. South East Asian Studies Manual 2000:112-120.

4. Sexually Transmissible Infections (CDC Guidelines). In: Nelson AL, Hatcher RA, Zieman M, Watt A, Darney PD, Creinin MD. editors. Managing contraception. Tiger, Georgia: Bridging the Gap Foundation, 2000.p.141-161.

5. Apea-Kubi KA, Addo VN. HIV/AIDS and other STDs. In: Kwawukume EY, Emuveyan EE. editors. Comprehensive gynaecology in the tropics. Accra: Graphic Packaging Ltd., 2005.

6. WHO. Sexually Transmitted and Other Reproductive Tract Infec-tions. Integrating STI/ RTI Care for Reproductive Health; A Guide to Essential Practice. Geneva: WHO, 2005.

7. Bang RA, Bang AT, Baitule M, Choudhary Y, Sarmukaddam S, Tale O. High Prevalence of Gynecological Diseases in Rural Indian Women. Lancet 1989;1(8629):85-7.

8. Oomman, N (Ed.). A decade of research on Reproductive Tract Infections and Other Gynecological Morbiditndia: What we know and what we don't know. New Delhi: Rawat Publications, 2000.

9. Patel BC, Khan ME. Reproductive Health Problems of Women in Rural Uttar Pradesh:
Observations from a Community Survey. Soc Change 1996. 26(3-4): 245-270.

10. Jejeebhoy S, Koenig M. The social context of gynaecological morbidity. In: Jejeebhoy S, Koenig M, Elias C. Eds. Research approaches to the study of reproductive tract infections and other gynaecological disorders. Cambridge University Press, Cambridge. 2002.

11. Bhanderi MN, Kannan S. Untreated reproductive morbidities among ever married women of slums of Rajkot city, Gujarat: The role of class, distance, provider attitudes and perceived quality of care. J Urban Health 2010;87(2):254-63.

12. Choi KH, Zheng X, Zhou H, Chen W, Mandel. Treatment delay and reliance on private physicians among patients with sexually transmitted diseases in China. Int $J$ STD AIDS. 1999;10(5):309-15.

13. Sihavong A, Lundberg L, Kounnavong S, Walstron R, Freudenkal S. Community perception and treatment seeking behavior regarding reproductive tract infections including STIs in Loa PDR a qualitative study. J Biosoc Sci 2011; 43(3):285-303.

14. Hegde SK, Agrawal T, Ramesh N, Sugara M, Joseph PM, Singh S, Thimmaiah S. Reproductive tract infections among women in a peri-urban under privileged area in Bangalore, India: Knowledge, prevalence, and treatment seeking behavior. Ann Trop Med Public Health 2013;6:215-20.

15. Prusty RK, Unisa S. Reproductive Tract Infections and Treatment Seeking Behavior among Married Adolescent Women in India. Mumbai: International Institute for Population Sciences, 2013.

16. Kulkarni AP, Baride JP, Doke PP, Mulay PY. Textbook of Community Medicine. $4^{\text {th }}$ Edition. Mumbai: Vora Medical Publication, 2013.

17. National AIDS Control Organisation. National STI/RTI Control and Prevention Programme NACP, Phase-III, India. New Delhi: National AIDS Control Organisation, Department of AIDS Control, MOH\&FW, 2007.

18. National AIDS Control Organisation, Simplified STI and RTI treatment guidelines, New Delhi: National AIDS Control Organisation, Department of AIDS Control, MOH\&FW, 1998.

19. Kumar S, Gupta SD, Kumar D, Singh JP, Bhawsar R. Reproductive tract infections and their associated risk factors among the women in Bundi district of Rajasthan. J Human Ecology 2002;13(4):307-10.

20. Prasad JH, Abraham S, Kurz KM, George V, Lalitha MK, John R. et al. Reproductive tract 
infections among young married women in Tamil Nadu, India. Int Fam Plan Perspect. 2005;31(2):73-82

21. Mani G, Annadurai K, Danasekaran R. Healthcare Seeking Behaviour for Symptoms of Reproductive Tract Infections among Rural Married Women in Tamil Nadu - A Community Based Study. Online J Health Allied Sci 2013;12 (3):3.

22. Radcliffe KW, Ahmad S, Gilleran G, Ross JD. Demographic and behavioural profile of adults infected with chlamydia: a case control study. Sex Transm Infect 2001;77(4):265-70.
23. Lassey AT, Adanu RM, Newman MJ, Opintah JA. Potential pathogens in the lower genital tract at manual vacuum aspiration for incomplete abortion in Korle Bu Teaching Hospital, Ghana. East Afr Med J 2004;81(8):398-401.

24. Parikh S, Brennan P, Boffetta P. Metaanalysis of social inequality and the risk of cervical cancer. Int J Cancer 2003;105(5):687-91.

25. Adanu RM, Hill AG, Seffah JD, Darko R, Anarfi JK, Duda RB. Sexually Transmitted Infections and Health Seeking Behaviour among Ghanaian Women in Accra. Afr J Reprod Health 2008;12 (3):151-8 